\title{
Caracterização da precipitação e sua relação com a evapotranspiração de referência em municípios do Piauí
}

\author{
Characterizing precipitation and its relation with the reference \\ evapotranspiration in cities of Piauí
}

\author{
Marcus Willame Carvalho', Catharina Teixeira Cortez", Adriana Conceição da \\ Silva"I', Gabriela Sabrine Franca Silva'v
}

\section{RESUMO}

A precipitação é uma variável de grande importância para a agricultura, sobretudo na região Nordeste do Brasil que sofre com intensos períodos de déficit hídrico. O objetivo deste trabalho foi caracterizar a precipitação dos municípios piauienses de Bom Jesus, Parnaíba, Picos e Teresina e observar a influência dessa variável climática sobre a evapotranspiração de referência. Os dados históricos mensais de precipitação dos anos 1994 a 2018 utilizados foram obtidos das estações meteorológicas do Instituto Nacional de Meteorologia (INMET) presentes nos municípios estudados. Realizou-se a análise exploratória, sendo obtidas, para cada mês do ano, as estatísticas: média aritmética $(\bar{x})$, desviopadrão (s), coeficiente de variação (CV), valor mínimo (Min) e valor máximo (Max), a fim de se verificar a dispersão dos dados, bem como a representação gráfica da distribuição das médias mensais da precipitação e a relação entre a precipitação e evapotranspiração de referência (ETo) para os municípios estudados. Os resultados evidenciam que há pouca variação dos períodos secos e chuvosos entre os municípios observados, porém há variação do volume de precipitação e da ETo. Observou-se que há relação inversa entre precipitação e evapotranspiração de referência para essa região.

Palavras-chave: caatinga; cerrado, Nordeste Brasileiro; bacia do Rio Parnaíba

\section{ABSTRACT}

Precipitation is a variable of great importance for agriculture, especially in the Northeast region of Brazil, which suffers from intense periods of water deficit. The objective of this work was to characterize the precipitation of Piauí cities and to observe the influence of this climatic variable on reference evapotranspiration. The monthly historical precipitation data from 1994 to 2018 were obtained from the meteorological stations of the National Meteorological Institute (INMET) of the cities of Bom Jesus, Parnaíba, Picos and Teresina. The statistical analysis was performed for each month of the year: arithmetic mean $(\overline{\mathrm{x}})$, standard deviation (s), coefficient of variation (CV), minimum value (Min) and maximum value (Max), in order to verify the dispersion of the data, as well as the graphical 'Doutorando em Agronomia na Universidade Federal do Piauí, Teresina, PI. E-mail: marcuswillame@hotmail.com ORCID: http://orcid.org/0000-0002-5882-7399

"Mestra em Agronomia pela Universidade Federal do Piauí, Teresina, PI. E-mail: txcatharina@gmail.com ORCID: http://orcid.org/0000-0003-2374-5323

"'Doutoranda em Agronomia na Universidade Federal do Piauí, Teresina, PI. E-mail: dricaconceicao@hotmail.com ORCID: http://orcid.org/0000-0002-0275-8777

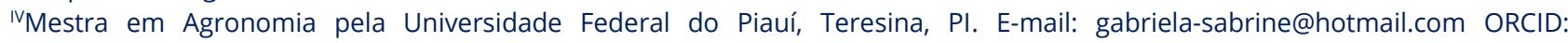
http://orcid.org/0000-0002-0348-5416 
representation of the distribution of monthly precipitation averages and the relation between the precipitation and reference evapotranspiration (ETo) for the municipalities studied. The results show that there is little variation in the dry and rainy periods between the municipalities observed, but there is variation in the volume of precipitation and ETo. It was observed that there is an inverse relationship between precipitation and reference evapotranspiration for this region.

Keywords: caatinga; savanna, Brazilian Northeast; Parnaíba Watershed

\section{INTRODUÇÃO}

A precipitação e a evapotranspiração são componentes importantes do balanço hídrico climatológico e correspondem ao incremento e as perdas de água, respectivamente, numa superfície cultivada. A água é a substância mais importante para a sobrevivência das espécies, devendo ser utilizada de forma racional, principalmente pela agricultura, que consiste no setor de maior consumo mundial desse recurso natural (PESSOA et al. 2016).

$\mathrm{Na}$ agricultura, informações quantitativas da precipitação e evapotranspiração são de grande importância na avaliação da severidade, distribuição e frequência dos déficits hídricos, elaboração de projetos e manejo de bacias hidrográficas e de sistemas de irrigação e drenagem (MOTTA PACA et al., 2019; VELOSO et al., 2012). Sobretudo na região Nordeste do Brasil, que está situada dentro da zona do semiárido, com grandes problemas para a sociedade e para os ecossistemas naturais, decorrentes das secas periódicas.

As variabilidades temporais e espaciais das precipitações pluviométricas constituem uma característica marcante do clima da região Nordeste do Brasil, em que a irregularidade temporal e espacial das chuvas constitui fator relevante, se não mais, do que os totais pluviométricos sazonais propriamente ditos, em especial para a agricultura de sequeiro, que depende da manutenção da umidade do solo durante o período de cultivo (MARENGO et al., 2011).

De acordo com Silva et al., (2017) a variabilidade da precipitação no Nordeste do Brasil é fortemente dependente da variação da temperatura do Atlântico, onde a elevação da temperatura no Atlântico Norte e diminuição no Atlântico Sul determinam as condições de seca e condições contrárias determinam as condições de chuva na região. 
Segundo Reboita et al., (2010) o Nordeste do Brasil é uma região relativamente seca com precipitação média anual inferior a $700 \mathrm{~mm}$. Esses baixos índices pluviométricos são decorrentes da atuação de movimentos subsidentes na região que fazem parte de uma circulação leste-oeste, na qual o ramo ascendente ocorre associado com a convecção da Amazônia e o descendente sobre o oceano Atlântico Sul.

O máximo de precipitação migra da região centro-oeste do Brasil, durante o verão (aqui correspondente ao mês de janeiro), para o norte do equador durante o inverno (representado pelo mês de julho), e a área com maior total de precipitação decresce bastante durante a transição do verão para o inverno (REBOITA et al., 2010).

O Piauí está localizado em uma zona de transição, apresentando, aspectos do semiárido nordestino, da pré-Amazônia e do Planalto Central do Brasil, refletindo as condições de umidade das diversas zonas. Apresenta caatinga arbórea e arbustiva, cerrado e cerradão, floresta decidual e formações pioneiras de restinga, mangue e aluvial campestre. No Piauí são identificadas duas características climáticas: tropical quente e úmido, e semiárido. Apresenta temperaturas médias elevadas, variando entre $18^{\circ}$ (mínimas) e $40^{\circ} \mathrm{C}$ (máximas). A umidade relativa do ar oscila entre 60 e 84\%. A frequência de chuvas diminui à medida que se avança para a região sudeste do Estado distribuindo-se de maneira irregular nesta região; porém, níveis anuais médios de precipitação abaixo de $800 \mathrm{~mm}$ são encontrados apenas em 35\% do território piauiense (GUEDES et al., 2010).

O conhecimento do regime de precipitação pluvial de uma região, no que diz respeito à duração e ao final da estação chuvosa, e a possibilidade de se conhecer períodos mais susceptíveis a estiagem dentro dessa estação, são fundamentais para a elaboração de um calendário agrícola e a implementação de projetos agropecuários (SILVA et al., 2011). Existem alguns trabalhos a despeito da caracterização pluvial da Bacia do Rio Parnaíba apenas na região de Teresina (MARCUZZO, 2019; MARCUZZO \& NASCIMENTO, 2018). Medeiros et al., (2016) analisando a distribuição temporal e a tendência da precipitação pluvial para o 
município de Bom Jesus - Pl observou que a tendência de maior variabilidade da precipitação concentra-se entre os meses de novembro a abril, e os menores índices pluviométricos entre os meses de maio a setembro.

De acordo com Ismael Filho et al., (2015), dentro do contexto da irrigação, o efeitos relativos das variáveis climáticas no processo de evapotranspiração é de fundamental importância, visto que grande parte do território nacional tem problemas com a disponibilidade de água, com elevados níveis de déficit hídrico, requerendo, portanto, o uso racional desse recurso natural.

Para um manejo racional da irrigação é de fundamental importância o conhecimento da evapotranspiração local a fim de se determinar a real necessidade hídrica de uma cultura. Existem alguns trabalhos com a determinação da ETo nos diferentes municípios do Piauí (Andrade Junior et al., 2017; Lucena et al., 2016; Silva et al., 2016), porém poucos fazem relação com dados históricos de precipitação, a fim de uma melhor caracterização destas variáveis na região. Diante do exposto, o objetivo deste estudo foi realizar uma caracterização da precipitação em diferentes municípios do estado do Piauí, e a influência da mesma sob a evapotranspiração de referência.

\section{MATERIAL E MÉTODOS}

\subsection{Dados}

Os dados históricos de precipitação e temperatura utilizados no desenvolvimento do presente trabalho foram disponibilizados pelo Instituto Nacional de Meteorologia (INMET). As estações estão localizadas em municípios que compõe a Bacia Hidrográfica do Rio Parnaíba (bacia de número 34) com uma área de 319.509 km² e corresponde a 3,84\% do Brasil (MARCUZZO, 2017). Foram selecionadas estações meteorológicas distribuídas em diferentes regiões do Estado e em municípios de grande importância econômica, sujeitos a diferentes regimes hídricos e condições climáticas como pode ser observado na Tabela 1 e 
no mapa da Figura 1. Os dados meteorológicos observados correspondem ao período de janeiro de 1994 a dezembro de 2018, totalizando 24 anos.

Tabela 1 - Coordenadas geográficas e caracterização climática por Thornthwaite \& Mather (1955) dos municípios onde estão localizadas as estações meteorológicas da análise.

\begin{tabular}{cccccc}
\hline Estação & Órgão & Latitude & Longitude & Altitude & Clima \\
\hline Bom Jesus & INMET & $9,1 \mathrm{~S}$ & $44,11 \mathrm{~W}$ & $331,74 \mathrm{~m}$ & Sub-úmido seco (C1) \\
Parnaíba & INMET & $3,08 \mathrm{~S}$ & $41,76 \mathrm{~W}$ & $79,50 \mathrm{~m}$ & Úmido (B2) \\
Picos & INMET & $7,03 \mathrm{~S}$ & $41,48 \mathrm{~W}$ & $207,93 \mathrm{~m}$ & Sub-úmido seco (C1) \\
Teresina & INMET & $5,08 \mathrm{~S}$ & $42,81 \mathrm{~W}$ & $74,36 \mathrm{~m}$ & Úmido (B1) \\
\hline
\end{tabular}

Fonte: Andrade Junior et al., (2004).

Figura 1 - Mapa do estado do Piauí com a localização dos municípios estudados.

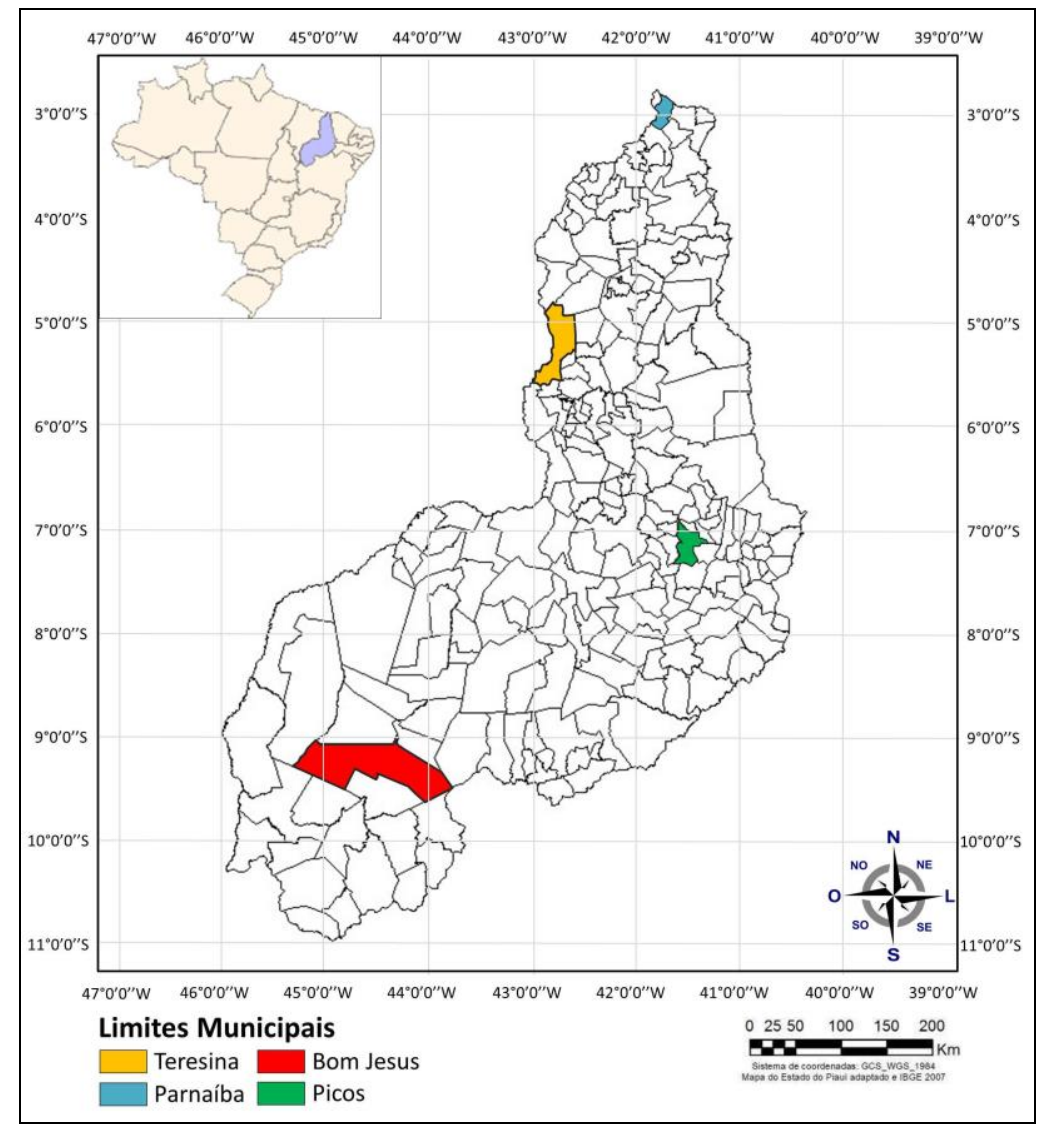

Fonte: Adaptado de IBGE

As falhas nas séries mensais foram preenchidas pelo método de ponderação regional (TUCCI, 2004). Para cada falha detectada em determinada 
estação meteorológica, procurou-se no conjunto de estações disponíveis no portal do INMET, três localizadas no entorno, o mais próximo possível daquela a ser preenchida, que possibilitassem a aplicação do método. Na impossibilidade da realização da ponderação, essa falha foi desconsiderada da análise. Para a estação de Bom Jesus foram observadas 11 falhas, para Parnaíba 1 falha, para, Picos 14 falhas e para Teresina foram observadas 8 falhas. Utilizou-se a ponderação apenas para o município de Bom Jesus, utilizando as estações de Caracol - PI (a 161 km), Vale do Gurgueia em Cristino Castro -PI (35,6 km) e Alto Parnaíba -MA (291km) e para Picos utilizando as estações de São João do Piauí (207 km), Campos Sales - PI (124 km) e Paulistana - PI (148km).

\subsection{Evapotranspiração de referência (ETo)}

Para o cálculo da variação mensal da Evapotranspiração de referência utilizou-se o método de Thornthwaite (1948) baseado na temperatura média do ar segundo as equações:

$$
\begin{gathered}
\text { ETo }=16\left(10 \frac{T_{i}}{I}\right)^{a}, 0^{\circ} \mathrm{C} \leq T_{i} \leq 26^{\circ} \mathrm{C} \\
\text { ETo }=-415,85+32,24 T_{i}-0,43 T_{i}^{2}, T_{i}>26^{\circ} \mathrm{C}
\end{gathered}
$$

em que, ETo é a evapotranspiração de referência $\left(\mathrm{mm}\right.$ mês $\left.{ }^{-1}\right)$, Ti é a temperatura do ar média mensal $\left({ }^{\circ} \mathrm{C}\right)$ e I é o índice térmico imposto pelo regime climático local, calculado por:

$$
\begin{array}{cc}
I=\sum_{n=1}^{12}\left(0,2 T_{i}\right)^{1,514}, T \geq 0^{\circ} \mathrm{C} & \text { Equação } 3 \\
a=6,75 \cdot 10^{-7} I^{3}-7,71 \cdot 10^{-5} I^{2}+1,7912 \cdot 10^{-2} I+0,49239 & \text { Equação } 4
\end{array}
$$

em que, i representa o mês do ano (i=1, janeiro; ...; i=12, dezembro).

As equações 1 e 2 fornecem a evapotranspiração para a condição padrão de meses com 30 dias e dias com 12 horas de brilho solar. Para obter a 
evapotranspiração mensal multiplica-se o valor obtido pelas equações 1 ou 2 pelo seguinte fator de correção (PEREIRA et al., 1997).

$$
C=\frac{N}{12}
$$

Equação 5

em que, N é o fotoperíodo de acordo com a latitude segundo Varejão-Silva (2005).

\subsection{Análise dos dados}

Realizou-se a análise exploratória das variáveis precipitações mensais, sendo obtidas, para cada mês do ano, pelo método estatístico descritivo: a média aritmética $(\bar{x})$, desvio-padrão (s), coeficiente de variação (CV), valor mínimo (Min) e valor máximo (Max), a fim de se verificar a dispersão dos dados. Fez-se, ainda, a representação gráfica utilizando programa Microsoft Excel (2010), da distribuição das médias mensais da precipitação, da relação entre a precipitação e evapotranspiração de referência (ETo), bem como da correlação entre os dados médios mensais de precipitação dos municípios. Utilizou-se a classificação de Pimentel Gomes, (1985) para o CV onde quanto menor o CV maior homogeneidade dos dados, seguiu-se a classificação para CV menores que 10\% são considerados baixos, entre 10 e 20\%, médios, entre 20 e 30\%, altos, e maiores que $30 \%$, muito altos.

\section{RESULTADOS E DISCUSSÃO}

As estatísticas descritivas das precipitações mensais dos municípios analisados estão presentes nas Tabelas 1 e 3. Segundo a classificação de Pimentel Gomes (1985), os coeficientes de variação (CV) da precipitação mensal (Tabela 1 e 2) mostram que a variabilidade desse atributo é relativamente alta. Observa-se que na estação seca a variabilidade se torna mais pronunciada com valores maiores que $30 \%$. Essa alta variabilidade pode ser explicada pela total ausência de chuvas em alguns anos da série, no período da seca.

Estes resultados concordam com os encontrados por Silva et al., (2011) avaliando a variabilidade da precipitação no Nordeste do Brasil, esses autores 
afirmam que os altos valores dos CVs da precipitação são associados à alternância de períodos secos e chuvosos, provocados pelos eventos de El Niño e La Niña, que ocorrem de forma recorrente na região, sobretudo na região do semiárido.

Tabelas 2 - Estatísticas da precipitação total mensal (mm) dos municípios de Bom Jesus e Parnaíba - PI, no período de 1994 a 2018.

\begin{tabular}{llllll|lllll}
\hline & \multicolumn{3}{l}{ Bom Jesus } & \multicolumn{1}{l|}{ Parnaíba } \\
\cline { 2 - 10 } Mês & $\mathbf{}$ & $\mathrm{s}$ & $\mathrm{CV}$ & Min & Max & $\mathrm{Q}$ & $\mathrm{s}$ & $\mathrm{CV}$ & Min & Max \\
\hline jan & 158,52 & 62,26 & 0,39 & 18,4 & 360,1 & 115,17 & 83,42 & 0,72 & 1,3 & 309,7 \\
fev & 152,73 & 70,95 & 0,46 & 34,6 & 322 & 171,96 & 96,35 & 0,56 & 25,2 & 385,6 \\
mar & 176,03 & 72,54 & 0,41 & 42,6 & 334 & 215,24 & 80,59 & 0,37 & 86,7 & 422,4 \\
abr & 110,74 & 71,15 & 0,64 & 8,9 & 304,6 & 223,61 & 110,03 & 0,49 & 47,9 & 421 \\
mai & 29,30 & 35,74 & 1,22 & 0 & 124,3 & 156,25 & 100,23 & 0,64 & 7,9 & 369,7 \\
jun & 0,79 & 2,09 & 2,64 & 0 & 8,8 & 50,14 & 34,45 & 0,69 & 0 & 121,2 \\
jul & 0,20 & 0,99 & 4,89 & 0 & 5 & 44,92 & 27,48 & 0,61 & 3,8 & 114 \\
ago & 1,05 & 3,85 & 3,65 & 0 & 17,4 & 4,72 & 9,43 & 1,99 & 0 & 44,6 \\
set & 16,82 & 33,78 & 2,01 & 0 & 165,5 & 1,01 & 2,63 & 2,59 & 0 & 10,2 \\
out & 66,34 & 60,24 & 0,91 & 0 & 215,4 & 2,73 & 9,09 & 3,33 & 0 & 44,4 \\
nov & 105,21 & 63,12 & 0,59 & 20,9 & 224,6 & 3,65 & 6,99 & 1,91 & 0 & 27,2 \\
dez & 156,32 & 82,19 & 0,53 & 11,4 & 341,1 & 20,80 & 25,36 & 1,22 & 0 & 92,6 \\
\hline
\end{tabular}

X - Média; s - Desvio Padrão; CV - Coeficiente de Variação; Min - Valor Mínimo; Max - Valor Máximo.

Tabelas 3 - Estatísticas da precipitação total mensal $(\mathrm{mm})$ dos municípios de Picos e Teresina - PI, no período de 1994 a 2018.

\begin{tabular}{cccccc|ccccc}
\hline & \multicolumn{5}{c}{ Picos } & \multicolumn{5}{c}{ Teresina } \\
\cline { 2 - 10 } Mês & $\mathbf{C}$ & $\mathrm{S}$ & $\mathrm{CV}$ & Min & Max & $\square$ & $\mathrm{S}$ & $\mathrm{CV}$ & Min & Max \\
\hline jan & 128,81 & 91,39 & 0,71 & 28,4 & 434,5 & 191,71 & 94,40 & 0,49 & 5,5 & 406,9 \\
fev & 129,84 & 77,63 & 0,59 & 8,8 & 300,5 & 233,87 & 102,81 & 0,44 & 82,8 & 530,2 \\
mar & 155,09 & 73,63 & 0,47 & 23,5 & 327,4 & 280,46 & 99,03 & 0,35 & 20,6 & 497,9 \\
abr & 106,18 & 73,65 & 0,69 & 5,9 & 279,9 & 270,54 & 136,41 & 0,50 & 81,8 & 569,8 \\
mai & 44,99 & 32,66 & 0,73 & 0,8 & 114,2 & 118,95 & 91,98 & 0,77 & 5,2 & 401,4 \\
jun & 3,21 & 5,94 & 1,85 & 0,0 & 26,7 & 16,56 & 16,31 & 0,98 & 0 & 74,7 \\
jul & 2,50 & 5,35 & 2,14 & 0,0 & 23,8 & 11,36 & 14,03 & 1,24 & 0 & 46,9 \\
ago & 0,32 & 0,89 & 2,80 & 0,0 & 4,2 & 5,27 & 10,06 & 1,91 & 0 & 48,1 \\
set & 2,44 & 5,15 & 2,11 & 0,0 & 22,0 & 9,38 & 12,93 & 1,38 & 0 & 47,1 \\
out & 20,52 & 26,87 & 1,31 & 0,0 & 105,1 & 25,16 & 35,76 & 1,42 & 0 & 167,6 \\
nov & 37,12 & 25,26 & 0,68 & 0,6 & 103,9 & 46,37 & 47,22 & 1,02 & 0 & 166,4 \\
dez & 88,39 & 51,59 & 0,58 & 13,8 & 270,4 & 97,02 & 79,55 & 0,82 & 9,9 & 370,6 \\
\hline
\end{tabular}

X - Média; s - Desvio Padrão; CV - Coeficiente de Variação; Min - Valor Mínimo; Max - Valor Máximo. 
A partir dos valores médios é possível observar pouca diferença entre as estações secas (junho a novembro) e chuvosas (dezembro a maio) para os diferentes municípios estudados, conforme Tabela 1 e 2 e Figura 2. Teresina apresentou maior volume de chuva com média anual de precipitação de 1300 $\mathrm{mm}$, sendo o período de dezembro a maio os meses mais chuvosos com volume superior a $90 \mathrm{~mm}$ (Figura 2D). O município de Parnaíba apresentou volume de $1010 \mathrm{~mm}$ de precipitação, sendo o período de chuvoso de janeiro a julho (Figura 2B). O município de Bom Jesus apresentou média anual de $974 \mathrm{~mm}$ com período de maior precipitação de novembro a abril (Figura 2A). Esses valores são semelhantes aos apresentados no Atlas Pluviométrico do Brasil com médias anuais relativas ao período de 1977 a 2006, sendo 1338 mm para Teresina, 1214 mm para Parnaíba e 846 mm para Bom Jesus.

Os maiores volumes de chuva em Teresina podem ser explicados pelas contribuições dos efeitos locais, como a proximidade aos rios Parnaíba e Poti, fatores que aumentam a cobertura de nuvens, a umidade relativa do ar e provocam chuvas de intensidades moderadas a fracas em quase todos os meses do ano, sendo o fenômeno La Niña o principal fator para ocorrência de chuvas acima da média histórica provocando inundações, alagamento, enchentes, enxurradas e desmoronamento (MENEZES et al., 2016).

Dentre os municípios analisados, Picos apresentou menor precipitação com volume de $719 \mathrm{~mm}$ sendo o período de maior precipitação de dezembro a abril (Figura 2C). Este resultado corrobora com os apresentados no Atlas Pluviométricos do Brasil com média de 774 mm. De acordo com Silva et al., (2010) devido a proximidade do município com o semiárido nordestino e seu posicionamento, desfavorece a atuação dos sistemas ondulatórios de leste, que são de extrema importância na umidificação da atmosfera, aumento de 
nebulosidade e precipitação sobretudo nos meses de agosto, setembro e outubro (COUTINHO et al., 2007). Sua variabilidade sazonal da precipitação apresenta máximo de 155,09 mm no mês de março, entretanto no mês de janeiro as médias apresentam-se elevadas, mostrando que além da Zona de Convergência Intertropical (ZCIT) outro sistema que também auxilia nos volumes de chuva, como os Vórtices Ciclônicos de Altos Níveis (VCANS) que atuam nos meses de janeiro e fevereiro (SILVA et al., 2010).

Observa-se que o período onde ocorrem as menores lâminas de precipitação, corresponde aos meses de junho a dezembro para o município de Parnaíba com contribuição de $12,67 \%$ do volume total. Já em relação ao município de Teresina esse período corresponde a junho a novembro contribuindo com $8,73 \%$ do total. Para o município de Picos a contribuição do período seco foi de 9,19\% correspondente ao período de junho a dezembro. Em Bom Jesus esse período corresponde aos meses de maio a junho com contribuição de $11,7 \%$ do volume total anual.

Figura 2 - Precipitação média mensal de Bom Jesus (A), Parnaíba (B), Picos (C) e Teresina (D) do período de 1994 a 2018.

A

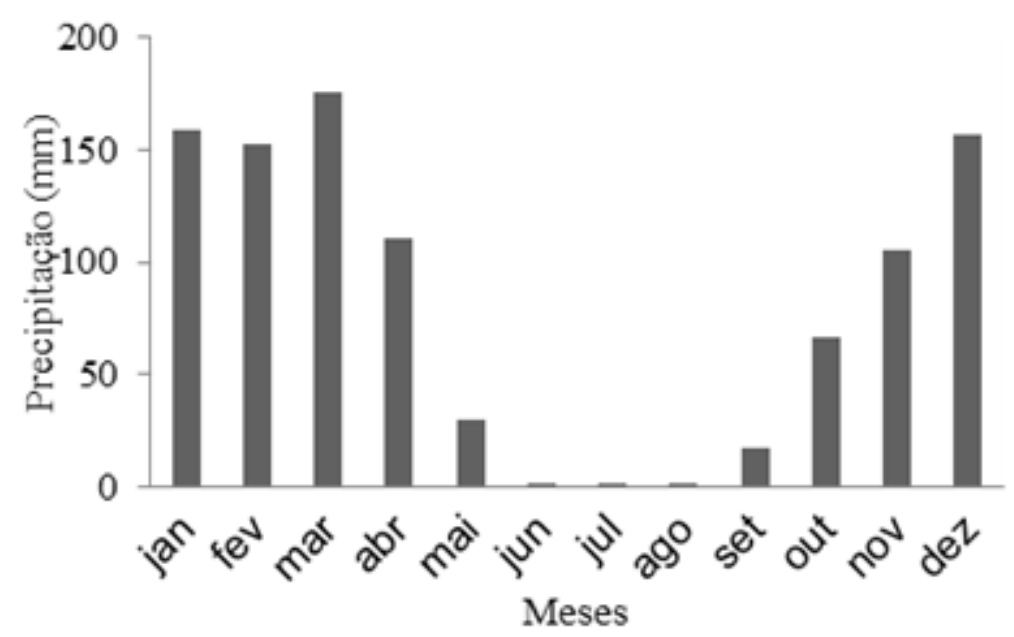

$\mathrm{B}$ 

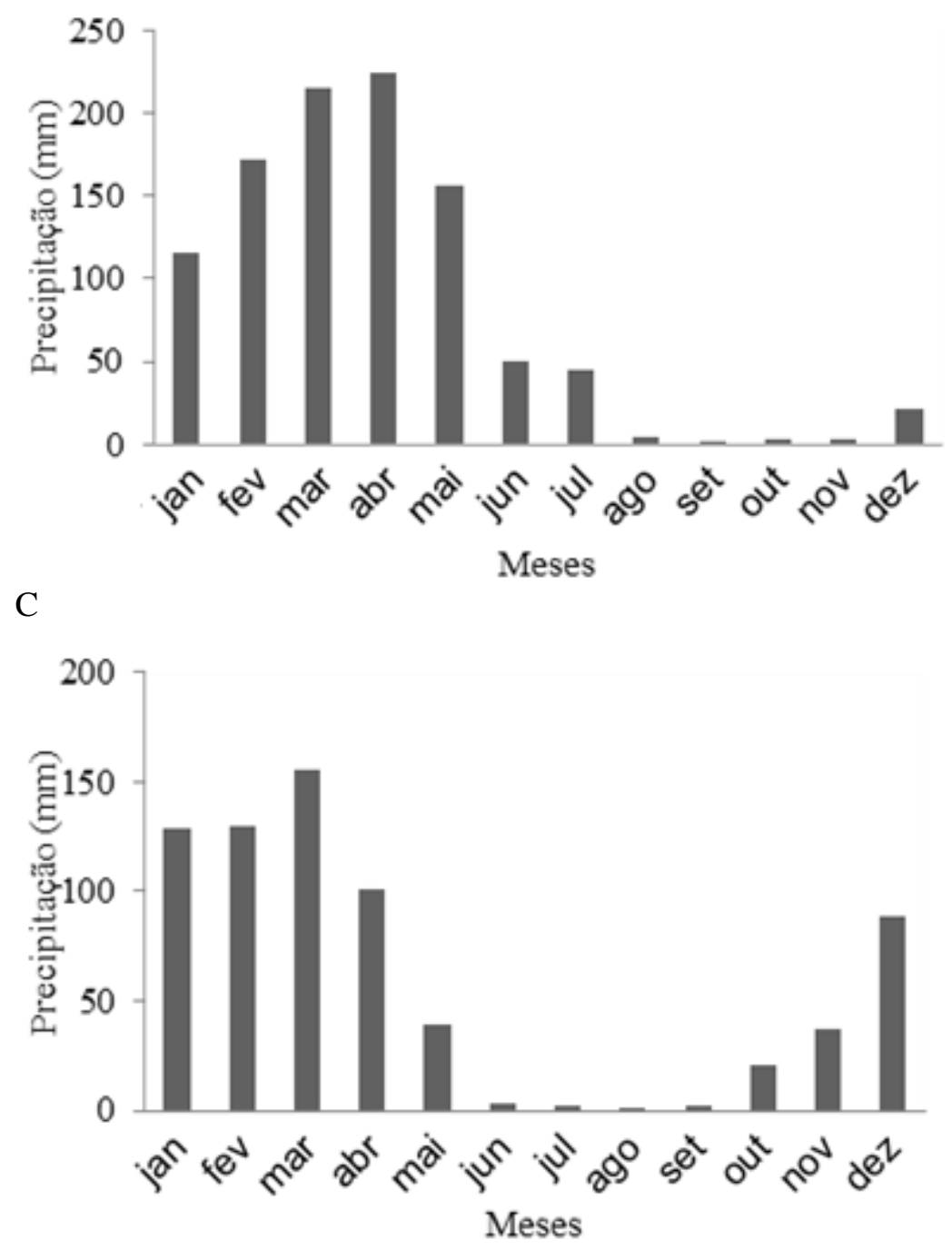

$\mathrm{D}$

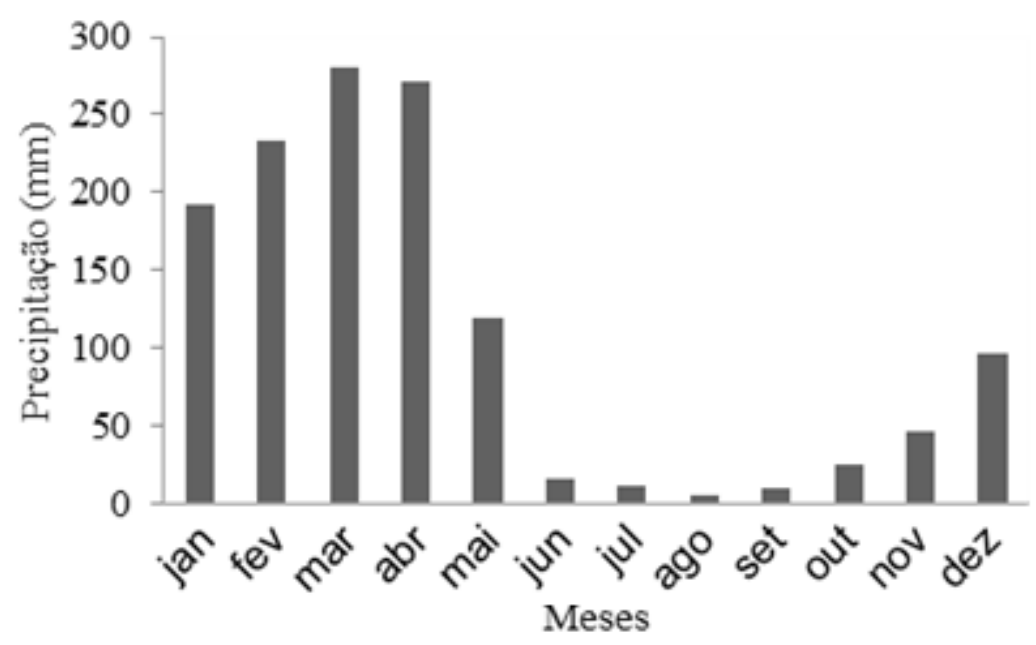

Assim como ocorre comumente na região Nordeste, a definição do período seco e chuvoso é decorrente da atuação de movimentos subsidentes. No inverno, agregada à subsidência da circulação Leste-Oeste, tem-se a subsidência associada à circulação de Hadley (a qual tem o movimento ascendente na região 
da ZCIT), e essa torna o inverno à estação mais seca. Por outro lado, a ZCIT no final do verão e início do outono, posiciona-se mais ao sul fazendo com que a pressão fique mais baixa na região do Nordeste do Brasil e, com a presença dos alísios, aumenta o transporte de umidade e favorece a precipitação (REBOITA et al., 2010).

Observa-se uma ampla variação nos valores mensais de ETo, onde os menores valores mensais foram registrados em Bom Jesus $(1.317,3 \mathrm{~mm}$ ) (Figura 3). De uma forma geral os municípios de Teresina, Parnaíba e Picos apresentaram valores semelhantes em torno de $(1.800 \mathrm{~mm})$. A diferença na altitude média foi o fator decisivo para essa variação nos valores mensais de ETo, uma vez que, à medida em que a altitude se eleva normalmente os valores de temperatura média tendem a ser menores, contribuindo para a redução da demanda evapotranspiratória da região (PEREIRA et al., 2018). De fato, a ETo anual do município de Parnaíba, onde a estação está localizada a 79,5 m, foi maior que a ETo do município de Bom Jesus com 331,74 m de altitude, indicando uma redução de 569,64 mm na ETo anual.

Observando a Figura 3, independentemente do município, nota-se que à medida que se eleva ou diminui a temperatura, a variação na ETo segue a mesma tendência. Oliveira et al., (2017) ressalta que o modelo para estimativa da evapotranspiração de referência de Thornthwaite, que é baseado, principalmente, na temperatura, tende a refletir apenas a sazonalidade intraanual, com taxas de ETo mais elevadas no período de primavera-verão. Além disso, este modelo tende a superestimar a ETo em dias de chuva, onde a radiação não é tão intensa e a umidade do ar é mais alta, ambas as variáveis não são utilizadas nesses modelos.

De acordo com Santos et al., (2016), a temperatura do ar é influenciada diretamente pela radiação, porém outros fatores também influenciam na variação, como umidade do ar, velocidade do vento, nebulosidade, altitude e 
advecção. Esses fatores contribuem para processos não lineares entre radiação e aquecimento do ar, e dessa forma, entre ETo e temperatura do ar.

Figura 3 - Média mensal da temperatura e evapotranspiração de referência por Thornthwaite (1948) de Bom Jesus (A), Parnaíba (B), Picos (C) e Teresina (D) do período de 1994 a 2018.

A

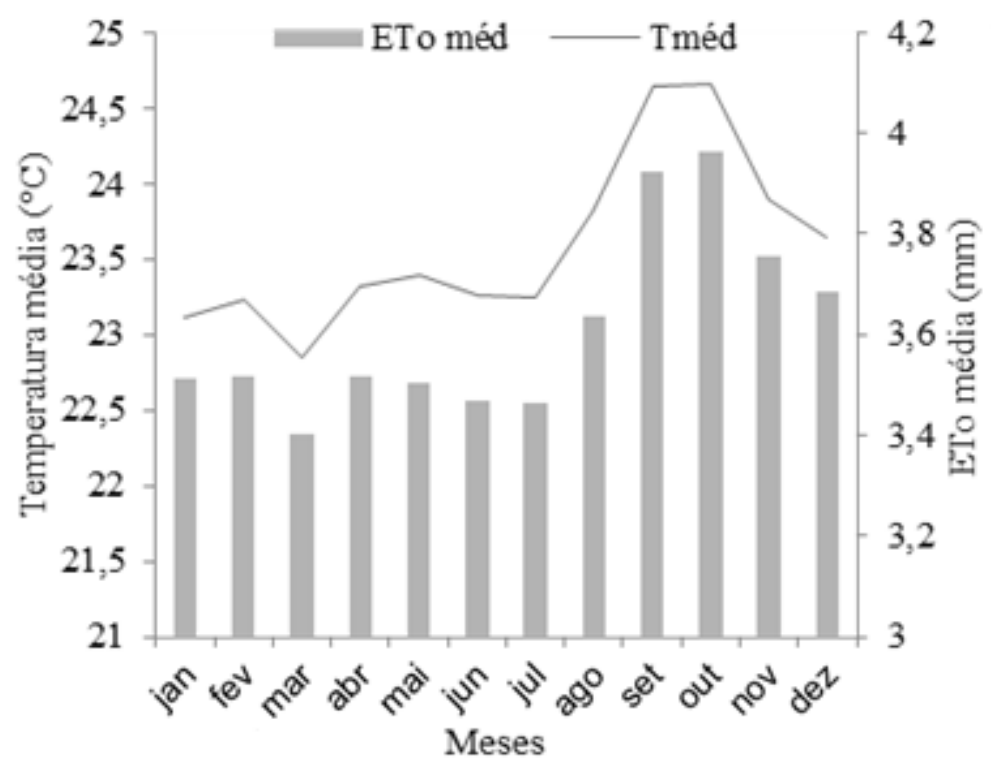

B

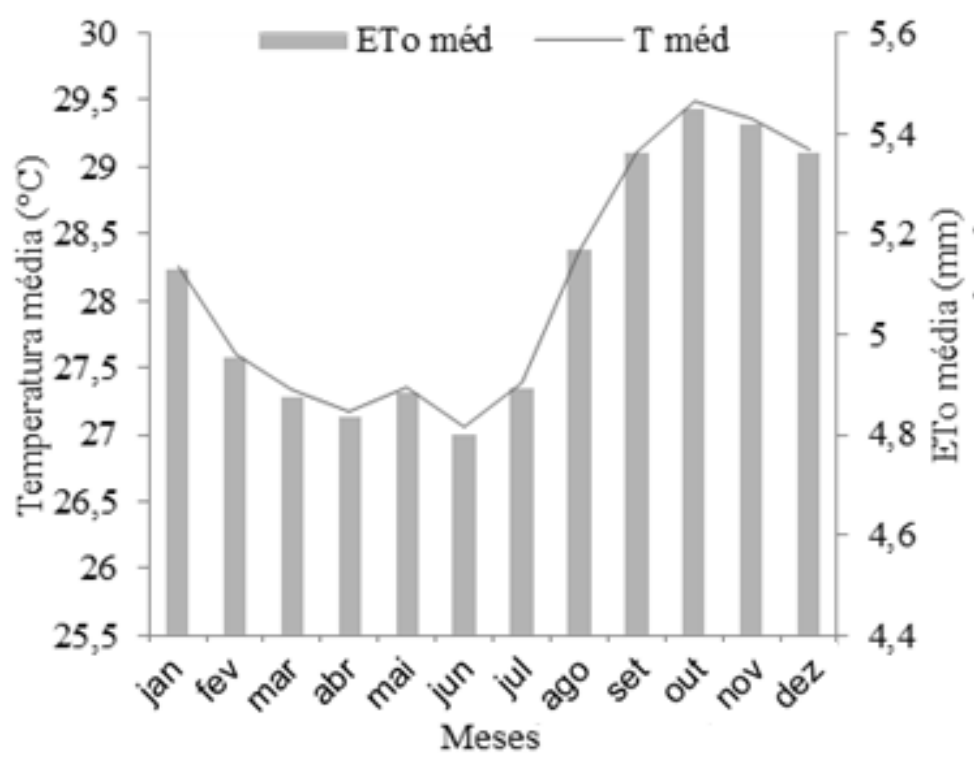

$\mathrm{C}$ 


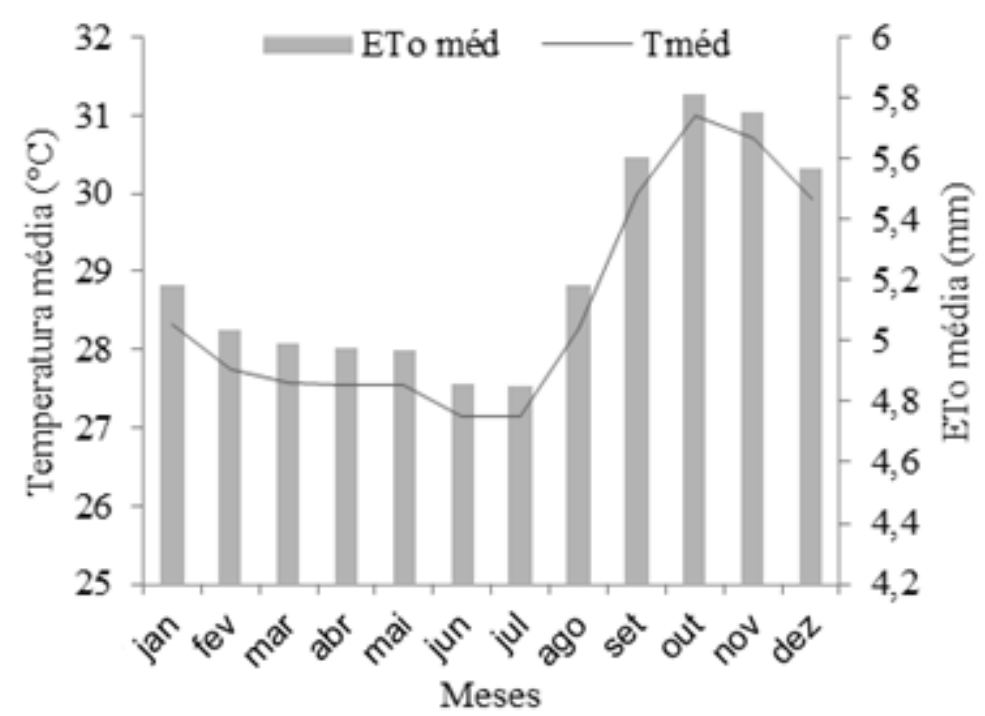

$\mathrm{D}$

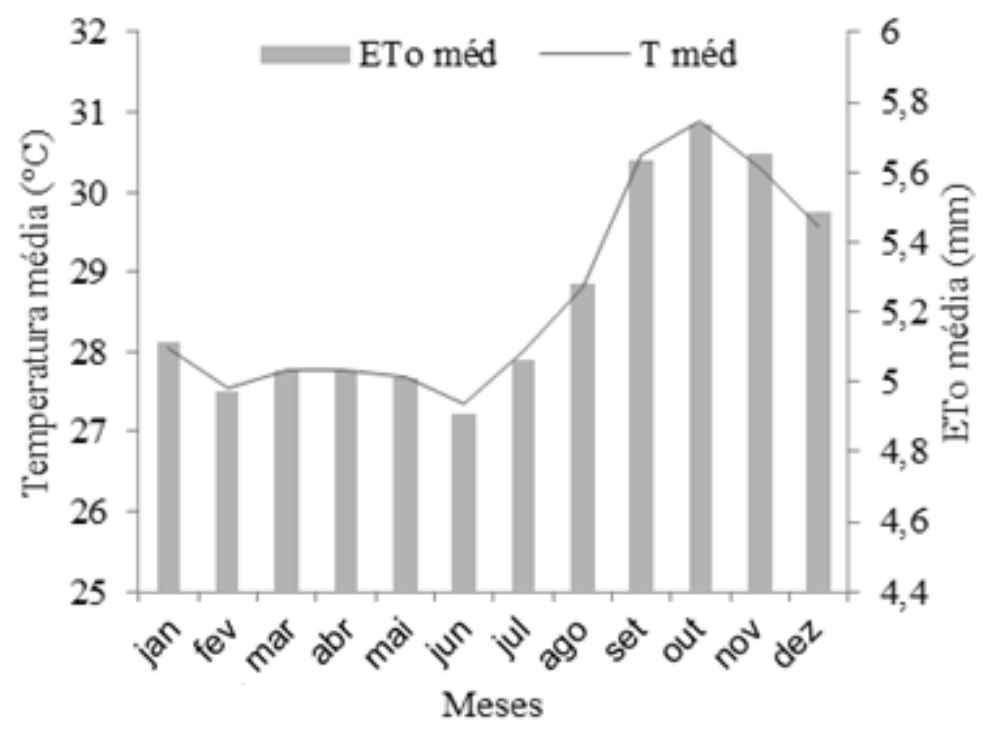

A ETo mensal dos municípios analisados apresentou ampla variação ao longo do ano, conforme variam os valores de temperatura média do ar e o regime de chuvas da região. Os valores mínimos ocorrem entre os meses de fevereiro a julho, enquanto os valores máximos se estendem de agosto a dezembro. Esses resultados concordam com os observados por Gomes et al., (2005) na determinação da ETo em vários municípios do Piauí, onde os valores mínimos (fevereiro a julho), com predomínio da classe de ETo de 100 a125 mm, enquanto os valores máximos (agosto a dezembro), com predomínio da classe de ETo de 150 a $175 \mathrm{~mm}$. 
Os valores máximos e mínimos de ETo correspondem aos períodos de ocorrência da estação seca e chuvosa, respectivamente, sendo um reflexo natural da variação espacial e da grande amplitude da temperatura média mensal nas diferentes regiões do Estado, a qual se acentua à medida que se afasta do litoral para o interior (Tubelis \& Nascimento, 1987). Conforme se observa na Figura 4 a relação entre a evapotranspiração e precipitação mensais ao longo do ano.

Em geral, observa-se uma relação inversa entre a evapotranspiração de referência e a precipitação. De acordo com Collischonn \& Tucci (2014) a relação inversa entre precipitação e ETo é explicada, principalmente, pela maior insolação e menor umidade do ar em dias secos, e em menor parte, pelo maior temperatura média do ar nestas condições.

Figura 4 - Relação entre os totais mensais de precipitação e evapotranspiração de referência (ETo) por Thornthwaite (1984) nos municípios de Bom Jesus (A), Parnaíba (B), Picos (C) e Teresina (D) no período de 1994 a 2018.

A

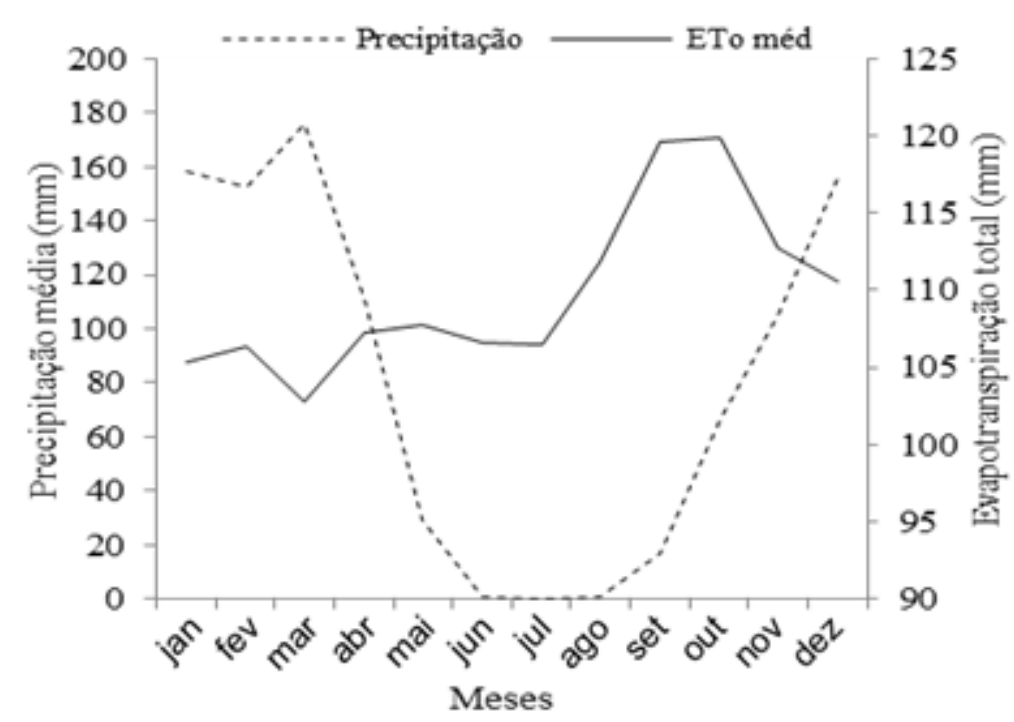

$\mathrm{B}$ 


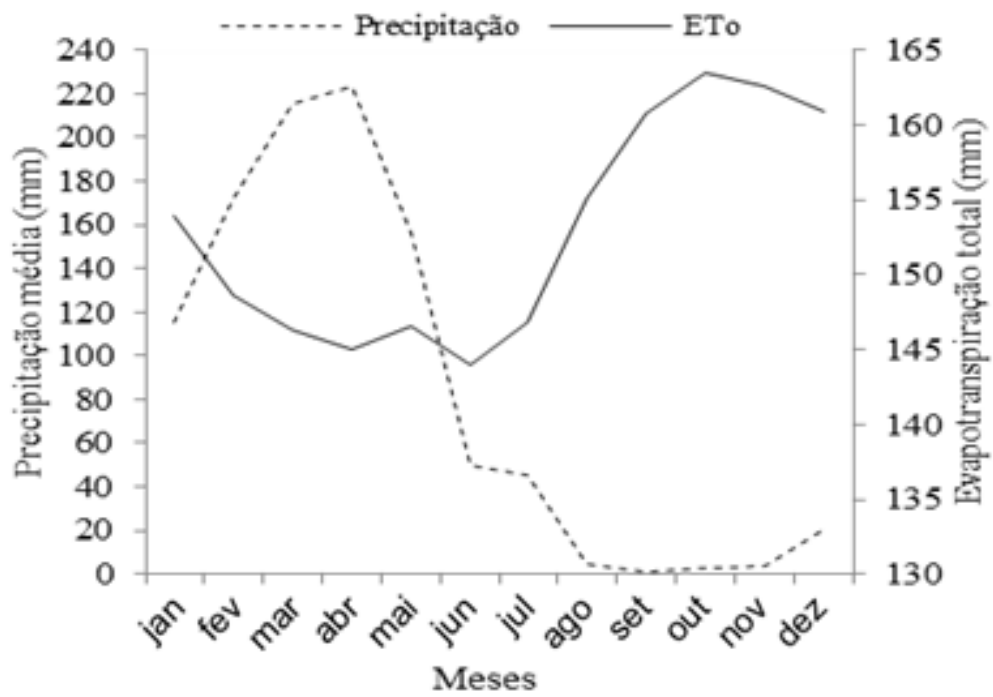

C

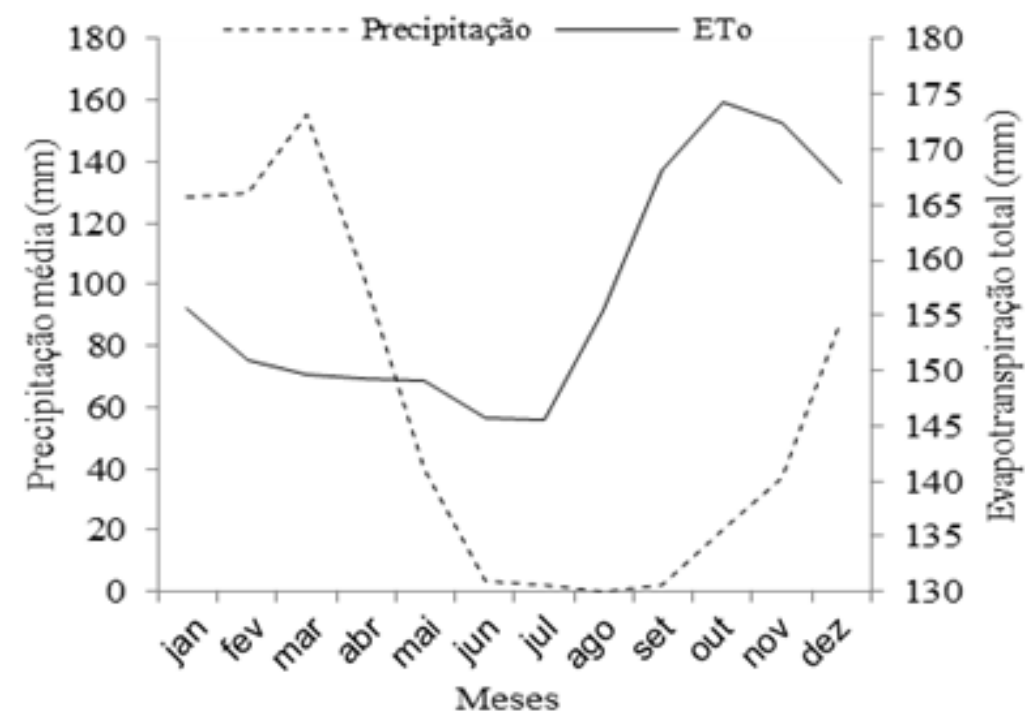

$\mathrm{D}$

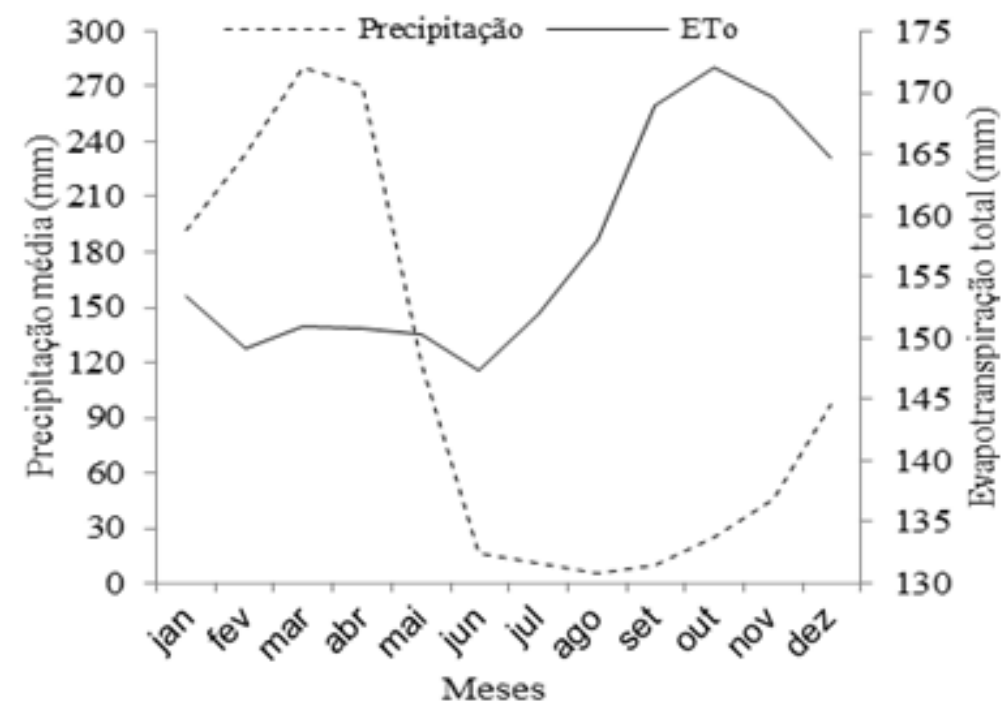




\section{CONCLUSÃO}

De acordo com as análises realizadas neste trabalho, observou-se que os municípios com maior volume de precipitação em ordem decrescente são os de Teresina seguido por Parnaíba e Bom Jesus. O município com menor volume de chuva foi o de Picos que devido ao seu posicionamento mais afastado do litoral (semiárido), há impedimento da ação dos sistemas ondulatórios de leste, que são de extrema importância na umidificação da atmosfera, aumento de nebulosidade e precipitação, além da sua localização no Bioma Caatinga que diferente dos demais estão localizados no Cerrado. Em relação à ETo os município com maiores volumes de perda de água, em ordem decrescente, são Teresina, Picos e Parnaíba. Os menores valores foram observados em Bom Jesus em decorrência da diferença de altitude entre os municípios de aproximadamente $254,5 \mathrm{~m}$ e menores medias de temperatura, que atuam diretamente no calculo da ETo.

A partir dos resultados obtidos foi possível observar semelhança entre os padrões de precipitação para os municípios avaliados, onde o período com maior precipitação vai de dezembro a maio e o período seco de junho a novembro. Observou-se também uma relação inversa entre a precipitação e a evapotranspiração de referência estimada por Thornthwaite, porém a ETo é, também, influenciada por outras variáveis climáticas como radiação e velocidade do vento que podem ser consideradas em outras equações de estimativa.

\section{REFERÊNCIAS}

ANDRADE JUNIOR, A. S.; BASTOS, E. A.; BARROS, A. H. C.; SILVA, C. O.; GOMES,A. A. N. Classificação climática do Estado do Piauí. Teresina: Embrapa Meio-Norte, 2004. Disponível em: <https://www.embrapa.br/busca-de-publicacoes//publicacao/68171/classificacao-climatica-do-estado-do-piaui>. Acesso em: 23 out. 2019.

ANDRADE JUNIOR, A. S.; DA SILVA, C. O.; DE SOUSA, V. F.; RIBEIRO, V. Q.. Avaliação de métodos para estimativa da evapotranspiração de referência no estado do Piauí. Agrometeoros, v. 25, n. 1, 2018. Disponível em: < 
http://seer.sct.embrapa.br/index.php/agrometeoros/article/view/26278>. Acesso em: 12 nov 2019.

ATLAS PLUVIOMÉTRICO DO BRASIL. Disponível em: < http://www.cprm.gov.br/publique/Hidrologia/Mapas-e-Publicacoes/AtlasPluviometrico-do-Brasil-1351.html>. Acesso em: 12 nov. 2019.

COLLISCHONN, B.; TUCCI, MORELLI, C. E. Relações regionais entre precipitação e evapotranspiração mensais. Revista Brasileira de Recursos Hídricos, Porto Alegre, v. 19, n. 3, p. 205-214, jul/set 2014. Disponível em: < https://www.researchgate.net/publication/305192645>. Acesso em: 05 nov. 2019.

COUTINHO, E. de C.; FISCH, G. Distúrbios ondulatórios de leste (DOLs) na região do Centro de Lançamento de Alcântara-MA. Revista Brasileira de Meteorologia, v. 22, n. 2, p. 193-203, 2007. Disponível em: < https://s3.amazonaws.com/academia.edu.documents/50395818>. Acesso em: 17 jan 2020.

GOMES, A. A. N.; ANDRADE JUNIOR, A. S. A.; MEDEIROS, R. M. Evapotranspiração de referência mensal para o estado do Piauí. Revista Brasileira de Engenharia Agrícola e Ambiental, v.9, n.4, p.560-564, abril 2005. Disponível em: < http://www.scielo.br/pdf/\%0D/rbeaa/v9n4/v9n4a19.pdf>. Acesso em: 05 nov. 2019.

GUEDES, R. S.; LOPES, F. J.; AMANAJÁS, J. C.; BRAGA, C. C. Análise em componentes principais da precipitação pluvial no estado do piauí e agrupamento pelo método de ward. Revista de Geografia. Recife, v. 27, n. 1, p. 218-233, 2010. Disponível em: < https://periodicos.ufpe.br/revistas/revistageografia/article/view/228794/23206>. Acesso em: 06 nov 2019.

ISMAEL FILHO, A.; BORGES, P. D. F.; ARAÚJO, L. D. S.; PEREIRA, A. R.; LIMA, E. D.; SILVA, L. D. S.; SANTOS JUNIOR, C. D. Influência das variáveis climáticas sobre a evapotranspiração. Gaia Scientia, v. 9, p. 62-66, 2015. Disponível em: < https://periodicos.ufpb.br/index.php/gaia/article/view/24072>. Acesso em: 06 nov 2019.

MANOSSO, F. C.; GOMES, M. F.; AOKI, A. Distribuição espacial e temporal da precipitação e temperatura média na região da serra do cadeado (PR). Revista Brasileira de Climatologia, Curitiba, v. 12, n. 1, jan/jul 2013. Disponível em: < https://revistas.ufpr.br/revistaabclima/article/view/27902/21513>. Acesso em: 06 nov 2019.

MARCUZZO, F. F. N. Bacias hidrográficas e regiões hidrográfi-cas do brasil: cálculo de áreas, diferenças e considerações. In: XXII Simpósio Brasileiro de Recursos Hídricos, 2017, Florianópolis. Anais... Porto Alegre: ABRH, 2017. p. 1-8. Disponível em: 
<http://rigeo.cprm.gov.br/jspui/bitstream/doc/18492/1/2017_sbrh_bacias_hidrografica s_brasil_artigo.pdf>. Acesso em: 02 dez. 2019.

MARCUZZO, F. F. N. Mapas da espacialização trimestral de chuva e hietograma trimestral da região metropolitana de Teresina, PI. 2019. 16 Simpósio de Geologia da Amazônia, Manaus. Anais... $2018 . \quad$ Disponível em: <http://rigeo.cprm.gov.br/jspui/handle/doc/21177>Acesso em: 06 nov 2019.

MARCUZZO, F. F. N.; NASCIMENTO, J. R. da S. do. Mapas da distribuição anual e mensal de chuva e hietrogramas da região metropolitana de Teresina, PI. 16 Simpósio de Geologia da Amazônia, Manaus. Anais... 2018. Disponível em: < http://rigeo.cprm.gov.br/jspui/handle/doc/20448 > Acesso em: 06 nov 2019.

MARENGO, J. A.; ALVES, L. M.; BESERRA, E. A.; LACERDA, F. F. Variabilidade e mudanças climáticas no semiárido brasileiro. Recursos hídricos em regiões áridas e semiáridas, Campina Grande, v. 1, 2011. Disponível em: < http://plutao.dpi.inpe.br/col/dpi.inpe.br/plutao/2011/09.22.18.52.30/doc/Marengo_Va riabilidade.pdf $>$ Acesso em: 06 nov 2019.

MEDEIROS, R. M.; DE ALCÂNTARA SILVA, V. M.; DA SILVA MELO, V.; MENEZES, H. E. A.; MENEZES, H. E. A. Diagnóstico e tendência da precipitação pluvial em Bom Jesus-Piauí, Brasil. Revista Verde de Agroecologia e Desenvolvimento Sustentável. v.11, n. 3, p. 115-121, 2016. Disponível em: < https://www.gvaa.com.br/revista/index.php/RVADS/article/view/3992/3803>. Acesso em 11 de dez de2019.

MENEZES, H. E. A; MEDEIROS, R. M.; SANTOS, J. L.G. Climatologia da pluviometria do município de Teresina, Piauí, Brasil. Revista Verde de Agroecologia e Desenvolvimento Sustentável. Pombal, v.11, n.4, p. 135-141, 2016. Dispnível em: < https://www.gvaa.com.br/revista/index.php/RVADS/article/view/4609/4012>. Acesso em: 06 nov. 2019.

NASCIMENTO, F. C. A; BRAGA, C. C.; ARAUJO, F. R. C. D. Análise Estatística dos Eventos Secos e Chuvosos de Precipitação do Estado do Maranhão. Revista Brasileira de Meteorologia. São Paulo, v. 32, n.3, p. 375-386, jul/dez 2017. Disponível em: <https://revistas.ufpr.br/revistaabclima/article/view/58267/36587>. Acesso em: 06 nov 2019.

OlIVEIRA, J. B.; BARBOSA, P. J. A.; NOGUEIRA, D. H.; ARAÚJO E. M.; ARRAES, F. D. D. Influência dos elementos meteorológicos sobre a evapotranspiração de referência em Tauá, no Ceará. Journal of Environmental Analysis and Progress. Recife, v. 02, n. 4, p. 403-411, ago $2017 . \quad$ Disponível em: <http://ead.codai.ufrpe.br/index.php/JEAP/article/view/1457/1448>. Acesso em: 06 nov 2019. 
PACA, V. H. M. da; ESPINOZA-DÁVALOS, G. E.; HESSELS, T. M.; MOREIRA, D. M.; COMAIR, G. F.; BASTIAANSSEN, W. G. The spatial variability of actual evapotranspiration across the Amazon River Basin based on remote sensing products validated with flux towers. Ecological Processes, v. 8, n. 1, p. 6, 2019. Disponível em: < https://link.springer.com/article/10.1186/s13717-019-0158-8> Acesso em: 06 nov 2019.

LUCENA F. A. P.; DA SILVA, E. M.; DE ALBUQUERQUE RIBEIRO, A.; SIMEÃO, M.; PEDROSA DE LUCENA, J. P. A. Comparação entre métodos de estimativa da evapotranspiração de referência no município de Bom Jesus, PI. Revista Brasileira de Agricultura Irrigada-RBAl, v. 10, n. 3, 2016. Disponível em: < http://inovagri.org.br/revista/index.php/rbai/article/view/404> Acesso em: 11 nov 2019.

PEREIRA, A. R.; VILLA NOVA, N. A.; SEDIYAMA, G. C. Evapotranspiração. Piracicaba: FEALQ, 1997. 183p.

PEREIRA, F. F. S.; PAI, E. D.; MONTENEGRO, R. J. V.; ROMÁN, R. M. S.; GONZÁLEZ, A. M. G. O.; ESCOBEDO, J. F. Estudo comparativo da evapotranspiração de referência entre localidades no estado de São Paulo e na província de Habana. Irriga, Botucatu, v. 21, n. 2, p. 395, maio/jun 2016. Disponível em: < http://revistas.fca.unesp.br/index.php/irriga/article/view/1858>. Acesso em: 6 nov 2019.

PESSOA, M. F.; ASSIS, L. F.; VIEIRA, A. S. Planejamento ótimo da água na agricultura irrigada: um estudo de caso em um perímetro paraibano. Revista Ibero-Americana de Ciências Ambientais, v. 07, n. 1, p. 221-234, 2016. Disponível em <http://www.sustenere.co/index.php/rica/article/view/SPC2179-6858.2016.001.0019>. Acesso em 01 de dez 2019.

PIMENTEL GOMES, F. Curso de estatística experimental. São Paulo: Nobel, 1985.

REBOITA, M. S; GAN, M. A.; ROCHA, R. P. DA; AMBRIZZI, T. Regimes de precipitação na América do Sul: uma revisão bibliográfica. Revista Brasileira de Meteorologia, São Paulo, v. 25, n. 2, junho 2010. Disponível em: <http://www.scielo.br/pdf/rbmet/v25n2/a04v25n2.pdf>. Acesso em: 06 nov 2019.

SANTOS, A. A. R.; LYRA, G. B.; LYRA, G. B.; LIMA, E. P.; SOUZA, J. L. DE; DELGADO, R. C. Evapotranspiração de referência em função dos extremos da temperatura do ar no estado do Rio de Janeiro. Irriga, Botucatu, v. 21, n. 3, p. 449, 2016. Disponível em: < https://www.researchgate.net/publication/309652190>. Acesso em: 06 nov 2019.

SILVA, V. P. R.; PEREIRA, E. R.; AZEVEDO, P. V. D.; SOUSA, A. S.; SOUSA, I. F D. Análise da pluviometria e dias chuvosos na região Nordeste do Brasil. Revista Brasileira de 
Engenharia Agricola e Ambiental, Campina Grande v. 15, n. 2, 2011. Disponível em: < http://www.scielo.br/pdf/rbeaa/v15n2/v15n02a04.pdf>. Acesso em: 06 nov 2019.

SILVA, A. P. N.; SOUZA, E. P.; VILHENA, N. Análise de clusters da precipitação do Estado do Piauí. XVI Congresso Brasileiro de Meteorologia. Belém. Anais... 2010. Disponível em: < http://www.sbmet.org.br/cbmet2010/artigos/251_86611.pdf> Acesso em: 06 nov 2019.

SILVA, C. O. D.; ANDRADE JUNIOR, A. S. D.; SOUSA, V. F.; RIBEIRO, V. Q.; SENTELHA, P. C.. Estimativa da evapotranspiração de referência com dados climáticos limitados no estado do Piauí. Espacios, v. 37, n. 23, p. 1-12, 2016. Disponível em: < https://www.alice.cnptia.embrapa.br/bitstream/doc/1064805/1/ArtigoAdersonRevEsp acios2016.pdf> Acesso em: 11 nov 2019.

SILVA, M. T.; ALCÂNTARA, C. R.; SOUZA, E. P. D.; OLINDA, R. A. D.; GONÇALVES, W. A. Influência da Temperatura da Superfície do Mar na Ocorrência de Linhas de Instabilidade na Costa Norte e Nordeste do Brasil. Revista Brasileira de Meteorologia, São Paulo, v. 32, n. 2, p. 260-268, 2017. Disponível em: < http://www.scielo.br/pdf/rbmet/v32n2/0102-7786-rbmet-32-02-0261.pdf> Acesso em: 06 nov 2019.

TUBELIS, A.; NASCIMENTO, F. J. L. Meteorologia descritiva: fundamentos e aplicações. São Paulo, Ed. Livraria Nobel, 1987. 221 p.

TUCCI, C. E. M. Hidrologia: ciência e aplicação. São Paulo: Editora da UFRGS, 2012. $943 \mathrm{p}$.

VAREJÃO-SILVA, M. A. Meteorologia e Climatologia. Recife, 2005.

VELOSO, G.; SANTOS, R. F.; SILVA, B. K.; DOLCI, B. D. Estimativa de evapotranspiração de referência para o município de Fernandes Pinheiro-PR. Acta Iguazu, Cascavel, v. 1, n. $1, \quad$ p. 15-22. Disponível em: < http://saber.unioeste.br/index.php/actaiguazu/article/viewFile/7024/5176> Acesso em: 06 nov 2019. 